\title{
Reproductive System Findings Supplemental Qualifiers Dataset
}

National Cancer Institute

\section{Source}

National Cancer Institute. Reproductive System Findings Supplemental Qualifiers Dataset. NCI Thesaurus. Code C147243.

A dataset containing supplemental information, specifically non-standard variables, to parent records in the reproductive system findings domain. 